\title{
АНТИМОНОПОЛЬНЫЙ КОМПЛАЕНС, КАК ЭЛЕМЕНТ БОРЬБЫ С КАРТЕЛЯМИ, ТЕОРИЯ И ПРАКТИКА. ЧАСТЬ 1
}

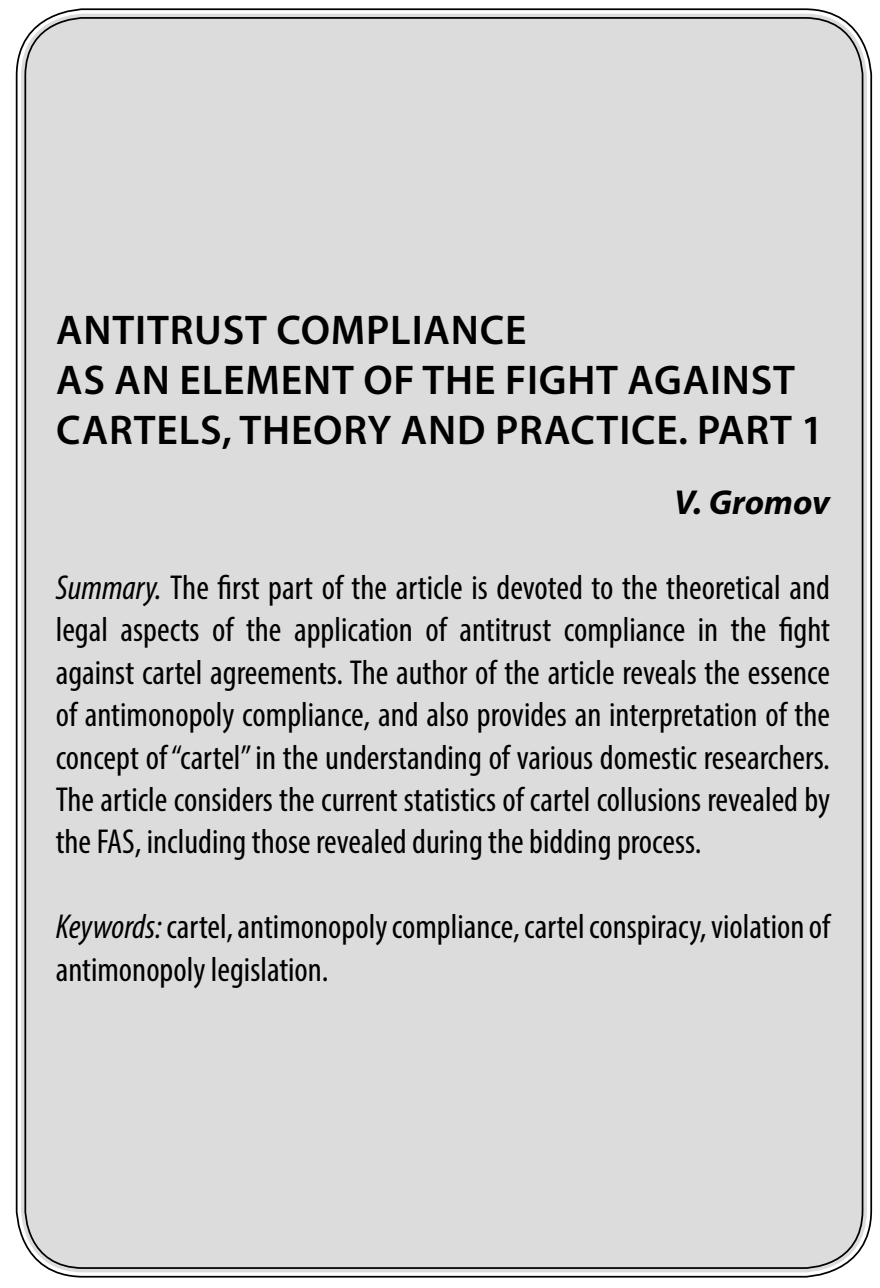

A ктуальность данного исследования обусловлена тем, что институт антимонопольного комплаенса в настоящее время выделяется в качестве эффективного элемента, позволяющего предупредить образование картелей. Системная работа по выявлению и пресечению картелей, сегодня получила серьезную значимость. Это подтверждается словами Президента РФ Путина В.В.: «государственные структуры и компании с государственным участием занимают те ниши, в которых мог бы работать малый и средний бизнес. Крупные игроки на рынке вытесняют небольших предпринимателей и монополизируют данные рынки. Таким образом, мы сталкиваемся с тем, что происходит непрерывный процесс картелизации различных конкурентных сфер российской экономики, а предпринимательская инициатива, а также стимулы к открытию собственного дела подрываются». Между тем, актуальность подтверждает-
Громов Валентин Валерьевич

Аспирант, Российская академия народного хозяйства и государственной службы при Президенте $P Ф$; Заместитель директора, $A O$ «Объединенная энергетическая компания»

Gromov_press@mail.ru

Аннотация. Первая часть статьи посвящена теоретико-правовым аспектам применения антимонопольного комплаенса в борьбе с картельными соглашениями. Автором статьи раскрывается сущность антимонопольного комплаенса, а также приводится трактовка понятия «картель» в понимании различных отечественных исследователей. Рассматривается современная статистика картельных сговоров, выявленных ФАС, в том числе, выявленных при проведении торгов.

Ключевые слова: картель, антимонопольный комплаенс, картельный сговор, нарушение антимонопольного законодательства.

ся увеличивающимся количеством научных публикаций на данную тему от различных отечественных авторов.

\section{Цe^ь}

Рассмотреть антимонопольный комплаенс в качестве эффективного элемента, позволяющего бороться с образованием картелей.

По нашему мнению, антимонопольный комплаенс выступает в качестве одного из наиболее эффективных элементов, позволяющих минимизировать риски, связанные с возникновением антимонопольных правонарушений.

К примеру, в зарубежных странах (Англия, США, Франция и т.д.), вопросы касающиеся антимонопольно- 


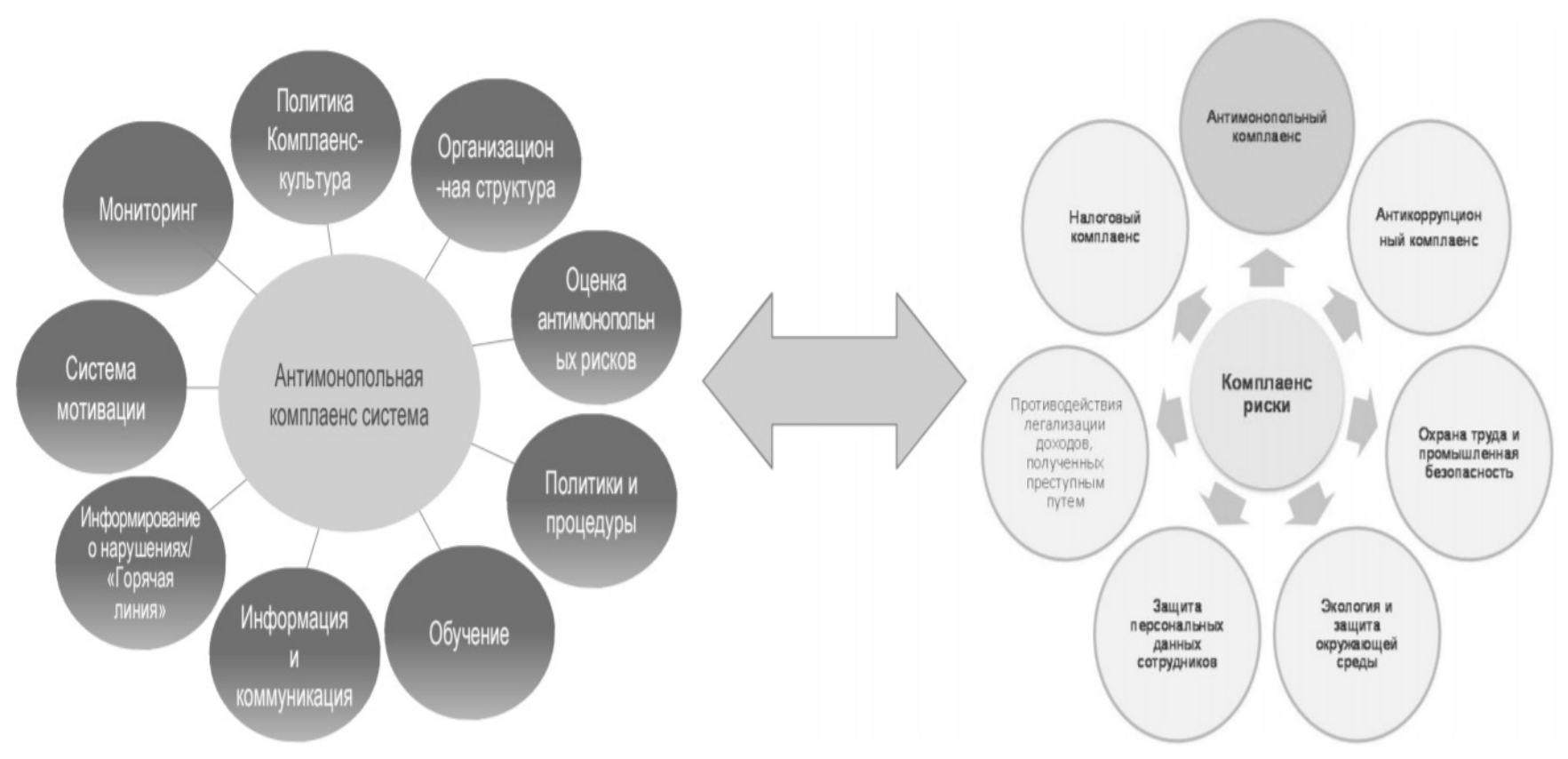

Рис. 1. Интеграция антимонопольного комплаенса в общую контрольную среду компании

го комплаенса, достаточно давно вселились в «умы» иностранных исследователей. Помимо этого, более давняя история характерна для риск-менеджмента в сфере антимонопольного регулирования вышеуказанных государств, например в сравнении с историей риск-менеджмента в России.

Первое упоминание термина «антимонопольный комплаенс» нашло отражение в стратегии, подготовленной Федеральной антимонопольной службой России в 2013 году, положив начало четырехлетней дискуссии научного сообщества относительно перспектив развития, значения, а также его практикоприменения в Российской Федерации.

Под комплаенсом следует понимать специальный элемент, который лежит в основе соблюдения антимонопольного законодательства хозяйствующим субъектом. В русскоязычном варианте «комплаенс» (от англ.compliance) предлагается называть как «систему внутреннего обеспечения соответствия требования антимонопольного законодательства» (ст. 9.1. Закона РФ «О защите конкуренции»).

Изначально, антимонопольный комплаенс был имплементирован в органах государственной власти и органах местного самоуправления. Об этом свидетельствуют следующие принятые нормативные акты:

- Указ Президента РФ от 21.12.2017 № 618 «Об основных направлениях государственной политики по развитию конкуренции»;
- Распоряжение Правительства РФ от 18 октября 2018 г. № 2258-p;

- Поручение руководителя ФАС России от 19.12.2018 № 01-047-РП/пр.

- Приказ Федеральной антимонопольной службы от 27 ноября 2018 г. № 1646/18 «О системе внутреннего обеспечения соответствия требованиям антимонопольного законодательства в ФАС России (антимонопольном комплаенсе)»;

- Постановление Правительства Москвы от 17 мая 2011 г. № 210-ПП;

С 01.03.2020 года, на основании Федерального закона № 33-Ф3 были внесены изменения в Федеральный закон № 135-Ф3 «О защите конкуренции». Фактически, только сегодня нам удается увидеть впервые закрепленное на федеральном уровне описание антимонопольного комплаенса применительно к хозяйствующим субъектам.

При этом, коммерческие компании, вследствие вывода своего бизнеса на международные площадки, также были ориентированы на повсеместное внедрение различных новых механизмов, одним из которых является антимонопольный комплаенс.

Результативность антимонопольного комплаенса уже давно доказана. Он используется во многих компаниях в зарубежных странах, а также успешно реализован в целом перечне российских. Среди которых: ПАО «НК «Роснефть», ПАО «Газпромнефть», ПАО «Лукойл», ГК 
«Автодор», ООО «ПК «Балтика», ПАО «Уралкалий», ПАО «МТС». Учитывая эффективность антимонопольного комплаенса, ему на сегодняшний день уделяется исключительное внимание, в том числе и на государственном уровне.

Что касаемо предпринимательской деятельности, то одной из характерных черт совершенствования ее антимонопольного регулирования стало существенное ужесточение антимонопольного законодательства. Указанные изменения можно наблюдать, как в отношении введения оборотных штрафов, так и в ужесточении уголовной ответственности, в случае если та или иная компания проявляет со своей стороны антиконкурентное поведение.

По логике вещей, данные меры должны в правильном направлении стимулировать деятельность хозяйствующих субъектов. Таким образом с их стороны должны быть выполнены определенные действия, которые позволят не допустить возникновения нарушений антимонопольного законодательства.

В основе антимонопольного комплаенса, лежат риск-ориентированные принципы. Именно поэтому антимонопольный комплаенс может быть интегрирован в общую контрольную среду организации, а также в ее отдельные контрольные системы.

Так, возможна интеграция с антикоррупционной комплаенс системой в части взаимодействия с контрагентами и проведении тендерных процедур, что является фактором, способствующим выявлению картельных соглашений (Рисунок 1).

Иными словами, институт антимонопольного комплаенса является эффективным элементом, который позволяет бороться с образованием картелей.

Как известно из истории, картелем изначально называли определенный письменный документ. Указанный документ описывал дуэльные и турнирные правила, а также вызовы на поединок. С течением времени, термин «картель» начал использоваться в том числе и в дипломатической практике, тем самым он обозначал определенные соглашения, которые не нуждались в ратификации.

В качестве экономического понятия, термин «картель» стал рассматриваться только с конца XIX века. Так, например, с точки зрения экономической теории, под картелем понимают одну из разновидностей монополий.

В современной юридической литературе понятие «картель» имеет различные трактовки, т.е. определяется неоднозначно. В свою очередь, различные отечественные ученые среди которых Кинёв А.Ю., Лашкин М.М., Шиткина И.С. и другие, внесли значительный вклад в изучение проблем картелизации российской экономики.

По мнению Кинёва А.Ю., которое он высказывает В рамках своей научной статьи «борьба с картелями в России», «картель - это сговор конкурентов, реализованный путем заключения незаконных соглашений, которые направлены на ограничение конкуренции, а также извлечение сверхприбыли».

Нельзя не согласиться с мнением Лашкина М.М., который в рамках своей кандидатской диссертации «Предпринимательская конкуренция в России: социально-экономический анализ» также предлагает собственное определение понятия «картель». Так картель по мнению Лашкина - это борьба компаний за ограниченный объем платежеспособного спроса и потребителей, которая осуществляется определенными субъектами хозяйствования на занятых ими сегментах рынка.

По мнению исследователя Шиткиной И.С., которое она высказывает в рамках учебного пособия по корпоративному праву, картель - это особая договорная форма объединения, в которую включаются различные хозяйствующие субъекты, непосредственные участники которой не теряют своей самостоятельности и преследуют цель расширить свои сферы влияния на товарных рынках.

В соответствии с Федеральным законом «О защите конкуренции», под картелем понимается соглашение, заключаемое между отдельными субъектами, которые в рамках одного товарного рынка выступают в качестве конкурентов. При этом данное соглашение должно приводить или способно привести к установлению, либо поддержанию стоимости, скидкам, надбавкам, наценкам и т.д.

В соответствии с действующим российским законодательством может быть составлена следующая классификация картелей:

1. ценовой картель - это соглашение между участниками рынка, в рамках которого проводится изменение стоимости на определенные товарные группы, либо услуги;

2. сговор на торгах - это периодически активизирующаяся группа лиц, которые ставят перед собой цель победы на определенных торгах для временной монополизации экономических отношений, непосредственно связанных с предметом торгов;

3. торговый картель - это картель, который создается с целью разделения рынка, например, по каким-либо определенным группам товаров; 
4. производственный картель - это картель, созданный с целью сокращения или полного прекращения выпуска определенных видов продукции;

5. ограничительный картель - это картель, функционирующий и обеспечивающий монополизацию определенного сектора рынка. В данном случае принуждение распространяется в отношении некоторых субъектов экономической деятельности в части их отказа от заключения договора на поставку товаров и оказание услуг с участниками рынка, не являющимися членами приоритетной группы для участников картеля.

В свою очередь, наиболее распространенные стратегии в отношении сговоров хозяйствующих субъектов, являющихся конкурентами представлены ниже:

- «Мнимая конкуренция («Торпеда», «Таран»). Со стороны непосредственных участников, вошедших в сговор, прослеживается демпинг, т.е. активная конкуренция, при этом цена снижается до такой степени, что участники торгов, преследующие добросовестные цели, и вовсе теряют интерес к подобному контракту. В свою очередь «недобросовестный» участник картеля в конечном итоге заключает контракт, но цена имеет минимальное снижение.

- Ротация победителей («Карусель», «Вальс»). В данном случае участники заранее осуществляют распределение торгов. После чего происходит подача мнимых заявок, либо их отзыв. Таким образом создается видимость конкуренции, и победа обеспечивается участнику, который был определен еще до начала торгов.

- Единственный победитель. В указанной ситуации происходит подача мнимых заявок, т.е. обеспечивается видимость конкуренции, при этом один определенный участник постоянно побеждает.

- Единственный поставщик. Участниками заранее определяются победители торгов. В свою очередь другие все кроме победителя сознательно отказываются от участия в «не своих» торгах.

Стратегии поведения в отношении сговоров заказчиков и участников, чаще всего выглядят следующим образом:

- «Заточки» в аукционной документации. Непосредственный заказчик торгов находясь в сговоре с участником, разрабатывает документацию, в которой указываются условия, соответствующие конкретному участнику, что фактически обеспечивает победу участника на торгах. Как правило, «заточки» противореча 223-Ф3 и 44-Ф3 и могут быть выявлены по средствам жалоб других участников.
- Лоббирование интересов «своих» участников. Документация в рамках рассматриваемой стратегии может полностью соответствовать законодательным требованиям. Добросовестные участники, как правило не участвуют в таких торгах, так как они не выгодны с экономической точки зрения.

- Передача полномочий организатора (заказчика) участнику. Заказчик на добровольной основе устраняется от выполнения своих обязанностей. Полномочия передаются определенному участнику торгов, который за заказчика проводит разработку всей аукционной документации, подписывает контракты, а в ряде случаев и вовсе отвечает на запросы других участников торгов».

Картельные сговоры, оказывают негативное влияние на экономику нашей страны. Дело в том, что участники картельных соглашений завышают стоимость без всяких на то оснований, что становится причиной снижения покупательской способности денег, а также объема спроса.

Борьба с картелями в России занимает главенствующие позиции: это законодательно было определено Национальным планом развития конкуренции до 2020 г.

Борьба с картельными соглашениями организуется в соответствии с Федеральным законом № 135-Ф3 «О защите конкуренции», а также КоАП РФ (административный запрет на заключение соглашений, ограничивающих конкуренцию). Помимо административной ответственности и гражданско-правовой предусмотрена ответственность уголовная, причем не только по ст. 178 УК РФ, но и по целому ряду других статей уголовного закона, в частности по ст. 204, 285, 286, 289 УК РФ. «Когда в игры с госзакупками вовлекаются органы государственной власти,- отмечает Тенишев А.П.,-это дважды нечестная конкуренция, вторая сторона которой - коррупция».

По словам президента Российской Федерации Путина В.В.: «Более жестокого наказания, чем нарушение антимонопольного законодательства, можно было представить себе только за государственную измену и за убийство. Я хочу, чтобы все это тоже услышали. Можно, конечно, и это всё либерализовать, но это ничего общего не имеет с вопросом административного давления на бизнес».

Согласно данным ФАС, в 2019 году было возбуждено 944 дела об антиконкурентных соглашениях. Из общего количества дел 424 дела было возбуждено именно по картельным соглашениям, а 320 из них было возбуждено в отношении сговоров на торгах. (Рисунок 2) 


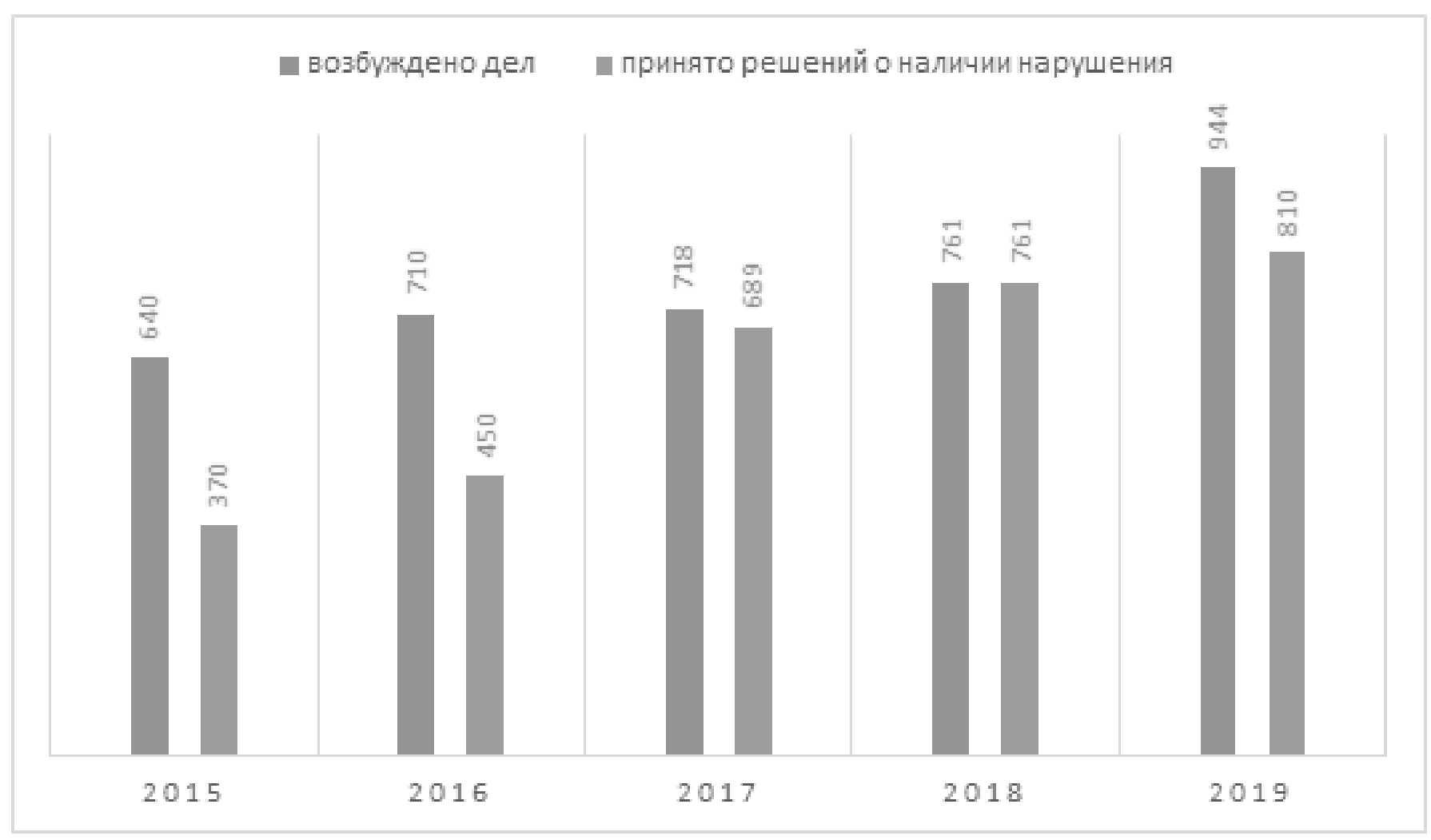

Рис. 2. Количество возбужденных дел и принятых решений по ст. 11, 11.1, 16 и п. 1 ч. 1 ст. 17

Статистика ФАС говорит о том, что на ежегодной основе количество возбужденных дел о нарушении антимонопольного законодательства, а также решений по ним растет. Например, в 2015 году было выявлено 640 случаев, по 370 из которых было принято решение. В 2019 году, было выявлено 944 нарушения и из них по 810 было принято решение.

Как заявил Тенишев А.П. (начальник управления по борьбе с картелями ФАС), «те нарушения, которые были выявлены за представленный период говорят о том, что картельные сговоры совершаются к настоящему моменту времени на совершенно любых видах торгов, а также в любых отраслях. По его мнению, картель к настоящему моменту времени - это один из основных вызовов финансового благополучия отечественной экономики. Она наносит значительный ущерб, а также приводит к серьезному регрессу. Именно поэтому крайне важно противодействовать, а также пресекать любые такие соглашения. Сегодня - это важнейшее направление, в котором работает ФАС, особенно в текущих условиях, когда ведется борьба с распространением коронавирусной инфекции».

Поэтому внедрение антимонопольного комплаенса может помочь уполномоченным органам власти учесть добросовестность поведения организации при привлечении ее к ответственности. Как отметил заместитель руководителя ФАС Пузыревский С., к хозяйствующим субъектам, внедряющим антимонопольный комплаенс, должны применяться стимулирующие меры, в частности, внедрение комплаенса должно рассматриваться как основание для смягчения административной ответственности за нарушение антимонопольного законодательства. Так, в ст. 14.32 КоАП РФ предусмотрены смягчающие обстоятельства при назначении административного наказания за заключение хозяйствующим субъектом соглашения, ограничивающего конкуренцию, осуществление ограничивающих конкуренцию согласованных действий, координацию экономической деятельности. Например, лицо, совершившее административное правонарушение, не является организатором ограничивающих конкуренцию соглашений, либо лицо не приступило к исполнению заключенного им ограничивающего конкуренцию соглашения.

При этом важно отметить, что антимонопольный комплаенс должен быть внедрен в организации-нарушителе ранее совершенного правонарушения - только в этом случае можно рассчитывать на признание наличия обстоятельства, которое смягчит административную ответственность. Иными словами, по антимонопольно- 
му комплаенсу должны быть предусмотрены другие модели, которые смягчат ответственность.

Однако, если перечень смягчающих административную ответственность обстоятельств будет расширен за счет внедрения антимонопольного комплаенса, то всегда найдутся те субъекты хозяйствования, которые будут пытаться уйти от ответственности, апеллируя к внедренному комплаенсу, т.е. в данном случае речь идет именно о формальном внедрении комплаенса.

Следует отметить, что такой опыт уже имеется в зарубежной практике. Как отмечает Пузыревский С., законодательству еще предстоит выработать формулу наказания компании, внедривший комплаенс лишь с целью ухода от ответственности.

Решение о внедрении антимонопольного комплаенса должно приниматься компаниями добровольно, о чем свидетельствует в том числе и мировая практика.
В основе комплаенс-контроля должны лежать принципы соответствия системы контроля организации значимым для осуществления деятельности факторам, ответственности органов управления за общий контроль в управлении комплаенс-рисками, соразмерности комплаенс-процедур потенциальным рискам, эффективности и открытости комплаенс-процедур, ответственности и неотвратимости наказания, регулярности комплаенс-контроля.

Таким образом, в заключении проведенного нами исследования удалось прийти к выводу, что антимонопольный комплаенс следует рассматривать в качестве эффективной элемента, который позволяет бороться с образованием картелей. Это подтверждается рассмотренными нами научными исследованиями, например, Тенишева А.П. Однако, данный элемент на сегодняшний день не совершенен и требует доработок, например, при принятии решений о смягчении административной ответственности.

\section{ЛИТЕРАТУРА}

1. Андрей Тенишев. Когда в игры с госзакупками вовлекаются органы государственной власти - это дважды нечестная конкуренция, вторая сторона которой — коррупция [Электронный ресурс].— Режим доступа: https://fas.gov.ru/news/26518 (дата обращения 02.02.2021)

2. Антимонопольный комплаенс в компаниях потребительского сектора [Электронный ресурс]. — Режим доступа: http://yatec.ru/upload/iblock/fa3/fa3a621 e35dedd66009812dd3829c1ba.pdf (дата обращения 18.01.2021)

3. Владимир Путин: Развитие конкуренции в стране... [Электронный ресурс].— Режим доступа: https://tver.fas.gov.ru/rtf/10289 (дата обращения 15.01.2021)

4. Горшкова, Е. Формула «скидки» за комплаенс / Е. Горшкова, С. Войниченко, Т. Радченко, В. Мартемьянов, А. Гаврилов. - Конкуренция и право. 2016. 一 № 2. - C. 41-46.

5. Журавлев С.Ю. Некоторые аспекты выявления и раскрытия картельных соглашений [Электронный ресурс] // Журавлев С.Ю., Малютина 0.А. — ППД. 2018. № 1. Режим доступа: https://cyberleninka.ru/article/n/nekotorye-aspekty-vyyavleniya-i-raskrytiya-kartelnyh-soglasheniy (дата 0бращения: 24.03.2021).

6. Иванов В. Антимонопольный комплаенс как новый инструмент антимонопольного регулирования предпринимательской деятельности // В. Иванов. Междисциплинарность науки как фактор инновационного развития. - 2017.—C. 146

7. Институт антимонопольного комплаенса как эффективный механизм предупреждения картелей [Электронный ресурс]. - Режим доступа: https:// regzdrav.ru/upload/iblock/433/Antimonopolnyi_-komplaens-i-karteli_SHCHerba-TE.pdf (дата обращения 02.02.2021)

8. Китаева Л.В., Картелизация российской экономики: факторы развития и преодоления [Электронный ресурс] // Л.В. Китаева, С.М. Ковалев. - Вестник экспертного совета. 2019. № 3 (18). Режим доступа: https://cyberleninka.ru/article/n/kartelizatsiya-rossiyskoy-ekonomiki-faktory-razvitiya-i-preodoleniya (дата обращения: 16.01.2021).

9. Лашкин М.М. Предпринимательская конкуренция в России: социально-экономический анализ: диссертация ... кандидата социологических наук: 22.00.03 / М.М. Лашкин. — [Место защиты: Моск. гос. ун-т им. М.В. Ломоносова].—- Москва, 2008.— 183 с. РГБ ОД, 61:08-22/41

10. Основания смягчения и освобождения от ответственности за нарушение антимонопольного законодательства [Электронный ресурс]. - Режим доступа: https://medium.com/@alina.smolyakova/основания-смягчения-и-освобождения-от-ответственности-за-нарушение-антимонопольного-2d75се8b5е6а (дата обращения 02.02.2021)

11. Официальный веб-сайт United Nations Conference on Trade and Developmen [Электронный ресурс].— Режим доступа: http://unctad.org/ru/docs/ tdrbpconf5d7rev3_ru.pdf (дата обращения: (22.01.2021)

12. Пузыревский С.0 новых законодательных инициативах ФАС. «Обязательным комплаенс для бизнеса не будет» / С. Пузыревский.- Газета Коммерсанть.-2018.- Июль.-С. 2.

13. Регламент N1435/2003 Совета Европейского Союза «06 Уставе Европейского кооперативного общества (SCE)» [рус., англ.], Принят в г. Брюсселе 22.07.2003 [Электронный ресурс]. Доступ из справочно-правовой системы «Консультант+».

14. Тесленко А.В. Уголовный кодекс — инструмент репрессии или защиты добросовестных предпринимателей // А.В. Тесленко. — Закон. 2018. № 8. С. 84-92;

15. Тесленко А.В. Наиболее распространенные стратегии реализации картелей и иных антиконкурентных соглашений на торгах // А.В. Тесленко. Журнал предпринимательского и корпоративного права. 2019. № 2. С. 4954. 
16. Тепляков С.Н. Сравнительный анализ антимонопольной политики Европейского союза и Российской федерации в области картельных соглашений // С.Н. Тепляков.— Современная конкуренция. М.: Управление Федеральной антимонопольной службы по г. Москве.— 2014.— № 3 (45). - С. $51-63$.

17. ФАС: в 2019 году выросло количество выявленных картелей [Электронный ресурс].— Режим доступа: https://fas.gov.ru/news/29669 (дата 0бращения 17.01.2021)

18. Черненко Т.И., Мировая практика борьбы с картелями и Российская система противодействия картелям // Т.И. Черненко, Л.А. Иванченко. 一 Актуальные проблемы авиации и космонавтики. Красноярск: Федеральное государственное бюджетное образовательное учреждение высшего образования «Сибирский государственный университет науки и технологий имени академика М.Ф. Решетнева», 2015.— № 11.— С. 616-617

19. Шиткина И.С. Корпоративное право: Учебный курс / И.С. Шиткина. — Москва: Статут, 2017. — 976 с.

(с) Громов Валентин Валерьевич (Gromov_press@mail.ru).

Журнал «Современная наука: актуальные проблемы теории и практики»

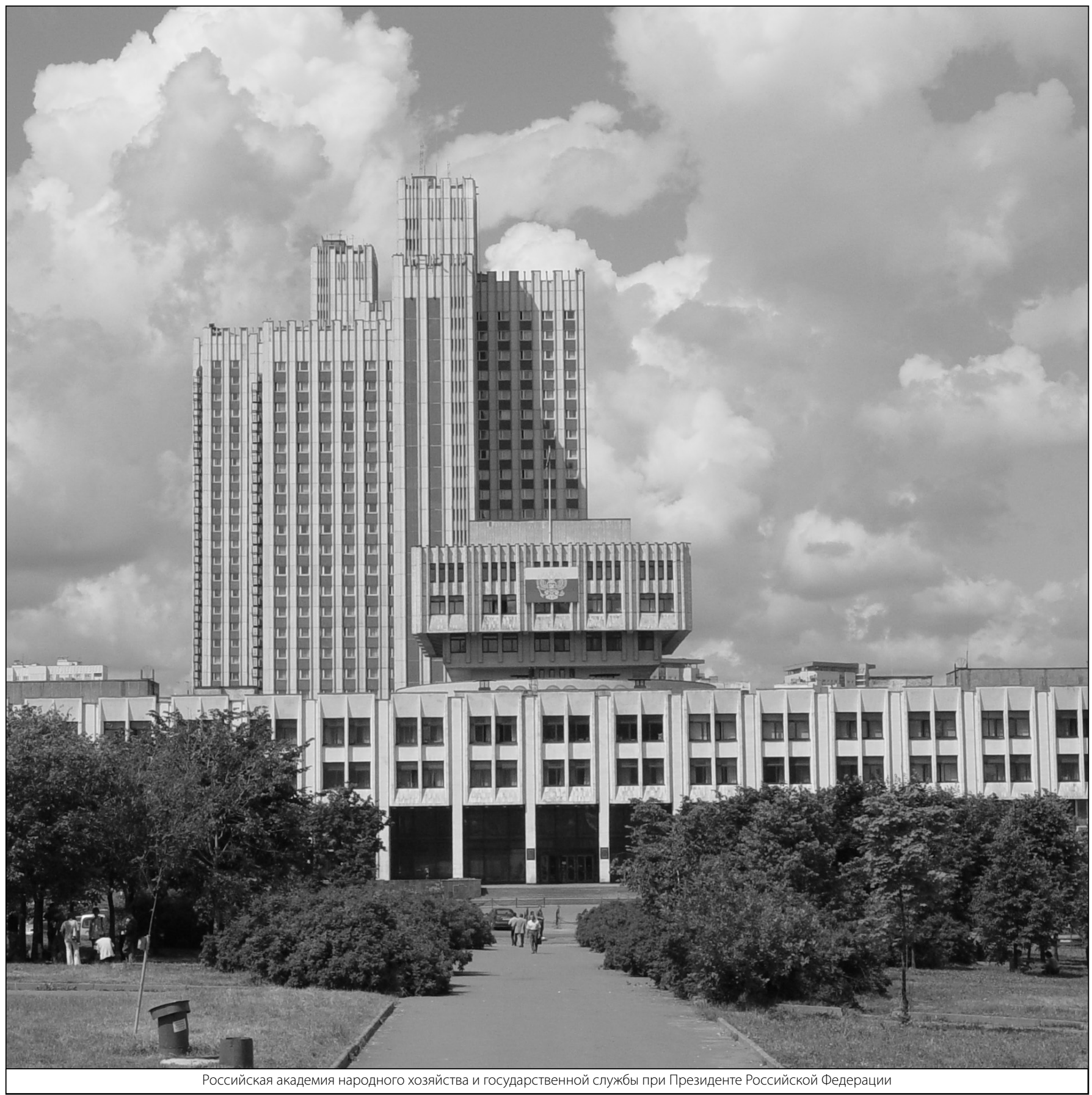

